\title{
Questioning technology's role in environmental ethics: weak anthropocentrism revisited
}

\author{
Shane Epting \\ Department of Philosophy, \\ University of Texas at El Paso, \\ Worrell Hall, El Paso, TX 79968, USA \\ Fax: 915-747-5403 \\ E-mail: freezepeach@hotmail.com
}

\begin{abstract}
Environmental ethics has mostly been practiced separately from philosophy of technology, with few exceptions. However, forward thinking suggests that environmental ethics must become more interdisciplinary when we consider that almost everything affects the environment. Most notably, technology has had a huge impact on the natural realm. In the following discussion, the notions of synthesising philosophy of technology and environmental ethics are explored with a focus on research, development, and policy.
\end{abstract}

Keywords: environmental ethics; technology; philosophy; sustainability; anthropocentrism; Hans Jonas; Aldo Leopold.

Reference to this paper should be made as follows: Epting, S. (2010) 'Questioning technology's role in environmental ethics: weak anthropocentrism revisited', Interdisciplinary Environmental Review, Vol. 11, No. 1, pp.18-26.

Biographical notes: Shane Epting is a graduate student at the University of Texas at El Paso. He has written and presented on a number of topics including sustainability, environmental philosophy, phenomenology, sustainable architecture, and ancient Greek wisdom. His current research focuses on developing a philosophy of sustainability that establishes and justifies responsible human-centred approaches toward the environment.

\section{Introduction}

Philosophy of technology and environmental ethics has mostly been practiced as separate disciplines, engaging each other in conversation only sporadically when some pressing issue brings them together. Problems arise because, on the one hand, they are often intertwined, and on the other hand, they lack common ground for conversation. Philosophy of technology does not offer any system of classification that allows us to build positions that are amiable towards environmental ethics. Yet, environmental ethics has many positions that are compatible with philosophy of technology. I argue that weak anthropocentrism suggests one possible synthesis. Weak anthropocentrism is the view, defined very loosely, that humankind is the prime ethical focus around which a systematic approach to the environment must be built and yet, the environment has room for consideration. 1 
This position allows us to approach problems in technology as they relate to the environment because technology is strictly a human-centred affair. If we can make the claim that technologies have embedded human values, then we can agree that technologies have environmental values embedded in them, too. After all, human values include environmental values. Even if the values embedded in technology do not mirror an image of environmental concern, nonetheless, they are a system of values, and they need questioning.

The following discussion exhibits how technologies fall into one of two categories: technologies that are considerate of the environment and those that are not. I argue that we should favour the former in all of our technological undertakings because they show more respect for the ecological integrity of nature, which benefits humankind. ${ }^{2}$ What is more humankind should promote technologies that respect nature's ecological integrity through research, development, and policy.

A correct approach to understanding the complexities of technology's relationship with the environment begins with a brief look at Aldo Leopold's revered text, A Sand County Almanac. One of the essential insights of this work is that he recognises the need to change the parameters of ethics, which is prescient to environmental ethics as a discipline. Leopold (1949, 1968, pp.202-203) asserts: "The first ethics dealt with the relation between individuals; the Mosaic Decalogue is an example. Later accretions dealt with the relation between the individual and society. The golden rule tries to integrate the individual to society; democracy to integrate social organisation to the individual. There is as yet no ethic dealing with man's relation to land and to the animals and plants which grow upon it."

This idea exhibits how he thought that the traditional scope of ethics falls short when it comes to the natural realm. Leopold $(1949,1968$, p.204) proposes the following 'land ethic' to amend these shortcomings: "The land ethic simply enlarges the boundaries of the community to include soils, waters, plants, and animals, or collectively: the land.... In short, a land ethic changes role of Homo sapiens from conqueror of the land-community to plain member and citizen of it. It implies respect for his fellow members, and also respect for the community as such." The apex of Leopold's ecological insights take the form of the following simple dictum that has become the backbone of environmental ethics: "A thing is right when it tends to preserve the integrity, stability, and beauty of the biotic community. It is wrong when it tends otherwise [Leopold, (1949, 1968), pp.224-225)."

Callicott (1989) developed Leopold's insights of concern into a methodological approach to ecocentric environmental ethics. Ecocentrism, defined loosely, is the view that the entire environment is the centre for moral consideration. ${ }^{4}$ Callicott (1989) asserts that ecocentrism wants to shift the centre of the environmental conversation from individuals to the ecosystem as a whole. While this view has its appeal, it goes against some widely held assumptions in Western civilisation. One can argue that a large percentage of people who are unaware or unconvinced of this position would agree that the environment does deserve consideration, but that humankind is the prime ethical focus for this consideration. This is the primary reason why we need to revisit weak anthropocentrism, especially when we address technology, which is purely anthropocentric. Leopold's thoughts laid the framework for the ecocentric position, but he did not focus on technology. Jonas (1985), like Leopold, has contentions about traditional ethics' inability to handle environmental troubles, but he focuses on technology. Jonas (1985, p.1) asserts: 


\begin{abstract}
"All previous ethics - whether in the form of issuing direct enjoiners to do and not to do certain things, or in the form of defining principles for such enjoiners, or in the form of establishing the ground of obligation for obeying such principles - has these interconnected tacit premises in common: that the human condition, determined by the nature of man and the nature of things, was given once for all; that the human good on that basis was readily determinable; and that the range of human action and therefore responsibility was narrowly circumscribed."
\end{abstract}

The benefits of human-to-human ethics were plentiful, and for all intended and relevant purposes, they still work well today for human-to-human problems. However, when we consider the impact that technology has had on the ecosystem, we find that these ethics lack the tools to get the job done correctly (Jonas, 1985). Jonas is writing in a technological context, and we can unpack the passage above better when we keep in mind another notion of his: "Modern technology has introduced actions of such novel scale, objects, and consequences that the framework of former ethics can no longer contain them [Jonas, (1985), p.6]." Jonas (1985) is aware that the scope of technology has evolved in a way that we can no longer have conversations about it and the environment together with valuable results under the ethics of antiquity. He points out the need for a new kind of ethics, which seems to anticipate the voice of today's environmental movement and echoes Leopold in many ways. Jonas puts forth ideas that seem to have an ecocentric mindset on the surface. Yet, we discover that they are weak-anthropocentric ideas when we analyse them critically:
"And what if the new kind of human action would mean that more than the interest of man alone is to be considered - that our duty extends farther, and the anthropocentric confinement of former ethics no longer holds? It is at least not senseless anymore to ask whether the condition of extrahuman nature, the biosphere as a whole and in its parts, now subject to our power, has become a human trust and has something of a moral claim on us not only for our ulterior sake but for its own and in its own right. If this were the case it would require quite some rethinking in basic principles of ethics. It would mean to seek not only the human good but also the good of things extrahuman, that is, to extend the recognition of 'the ends in themselves' beyond the sphere of man and make the human good include the care for them." [Jonas, (1985), p.8]

Although the above-mentioned passage has an ecocentric ring to it, this is only indicative of the environmentally friendly mindset that ecocentrism and weak anthropocentrism share. Jonas (1985) argues that we must recognise the interests and intrinsic value of nature, and we must make the human good include considering what is good for the biotic community. This new ethic is centred on humankind, but the environment is a consideration. Therefore, it is a weak anthropocentric ethic. ${ }^{5}$ What is more the passages mentioned previously culminate in an evident anthropocentric imperative: "Act so that the effects of your action are compatible with the permanence of genuine human life [Jonas, (1985), p.11]." This imperative is reconcilable with Leopold's dictum because it suggests that humans can only live and thrive if the environment lives and thrives. If we focus our attention on a weak anthropocentric position that has an environmentally friendly mindset, we have an approach that is helpful to the technology-environment conversation.

It is easy to focus on the differences between ecocentrism and weak anthropocentrism, but this does not advance the conversation significantly. While weak anthropocentrism does provide a synthesis of philosophy of technology and 
environmental ethics, we can transcend the distinction between ecocentrism and weak anthropocentrism, at least as far as it relates to technology. We can accomplish this by focusing on the similarities, such as concern for nature, and advance the conversation into the realm of applied (environmental) ethics. Then, we have the ability to approach problems in technology and achieve an ecologically friendly solution on a case-by-case basis as each case relates to the whole ecological crisis. This mutual concern for the environment helps synthesise Leopold's dictum and Jonas' imperative. This is the ecological imperative of technology: approach technology in a manner that is conducive to the permanence of genuine human life, which requires ecological sustainability.

By 'genuine human life', Jonas was not talking about measuring achievement in terms of gross national product. He was talking about the genuine human life in the classical sense, as in human flourishing. This, however, is an entirely different point. This discussion unfortunately does involve topics like gross national product in terms of technological research, development, and policy. This means that we must look at the dichotomous nature of technology. In order to grasp this dichotomy, we will look at technology through the eyes of Martin Heidegger by way his influential work, The Question Concerning Technology.

Heidegger (1977, 1993, pp.319-325) classifies technology in two categories: revealing and enframing. Revealing technology involves humankind discovering the hidden potential that nature has, such as a windmill [Heidegger, (1977, 1993), p.320]. One particular feature of the windmill is that it cooperates with nature by exhibiting how it and nature produce power together. It respects the ecological integrity of nature because the windmill does not harm the environment to a significant degree. Enframing technology, on the other hand, is a type of revealing technology that challenges nature without respect for its ecological integrity [Heidegger, (1977, 1993), p.321]. Enframing involves turning nature into a 'standing reserve' for human production [Heidegger, (1977, 1993), p.320]. Heidegger (1977, 1993) provides the hydroelectric dam as an example of this type of technology. As a result of humankind's use of enframing technologies, we can argue that nature's ecological integrity has not been considered. This lack of consideration set the stage for the current ecological crisis.

\section{Technological research and development and the environment}

If we are to combat (and prevent) environmental degradation, it must be an interdisciplinary undertaking. Some of the most influential areas are technological research and development and technology and environmental policy. They must all favour nature's ecological integrity as much as possible. For this purpose, we need a way to talk about technology in a systematic vocabulary. Within Leopold's dictum, there is a designation of the terms 'right' and 'wrong'. The terms are applied properly when 'a thing' does or does not promote the integrity, beauty, or stability of the biotic community. ${ }^{6}$ We can assume that 'a thing', for the purpose of this discussion, is a technology. From these designations, we can take an additional step and say that a thing being right is an ethically good technology, and we can say that a thing being wrong is an ethically bad technology. However, when it is difficult to argue that a technology is either 'good' or 'bad', we can replace 'good' with 'better' and 'bad' with 'worse' when it is more appropriate. When we are able to make these measurements, we can promote the technologies that favour nature's ecological integrity the most. 
For instance, one can argue that cars are largely responsible for the alarming amount of carbon dioxide in the atmosphere. Yet, it is the combustion of fossil fuels that has made the most hazardous contribution. If humankind wants to reduce the amount of carbon dioxide in the atmosphere, then one strategy would be to promote alternatively fuelled cars such as hybrids. Hybrid cars still pollute, but they pollute less. Therefore, they are better technologies. If we evaluate automobiles by the amount of carbon dioxide that they release into the atmosphere, then we can promote the ones that go to greater lengths to respect the natural realm. The values embedded in these types of technologies exhibit more respect for the integrity of the environment. It is worth mentioning that all aspects of the automobile manufacturing process have to be addressed in order to assess the impact that they have on the environment, but for the purposes of this discussion, we will limit ourselves to the final product. ${ }^{7}$

When we talk about technologies such as automobiles, it is relatively easy to categorise them as technologies that favour revealing or enframing. However, the issue becomes cloudier when devices such as the personal computer come up. When we consider that computers and other electronic devices harm the environment, we see that these devices do not have positive environmental values embedded in them. For instance, The Environmental Protection Agency estimates that between 2000 and 2007, US disposed of at least 500 million personal computers, which entered the municipal solid waste stream. ${ }^{8}$ In 2007 alone, US disposed of 2.5 million tons of TVs, computers, cell phones and other devices, and these devices contain harmful substances such as lead and mercury. ${ }^{9}$ This type of disposal reflects on our environmental values. By disposing of our obsolete electronic devices in a hasty fashion, our behaviours reflect an attitude that construes the natural realm as a standing reserve for waste. ${ }^{10}$ A correct approach to this problem begins with the research and development of electronics that lean more in the direction of the integrity found in revealing technology.

This is not just an environmentally friendly pipedream. Rather, computer design is slowly but surely moving in the direction of preserving nature's ecological integrity. Somewhat recently, companies introduced lead-free computers that do a much better job of being environmentally friendly than other models on the market. ${ }^{11}$ The designers of these computers go to greater lengths to preserve the integrity of the biotic community than their predecessors did. Therefore, they are a better technology. This type of production reflects a better sense of environmental values. Researchers can study the impact that new technologies have on the environment. Palm and Hansson (2006) propose a nine-point checklist outlining the pressing areas of technological research and development, one of which question technology's impact on the ecosystem. Palm and Hansson (2006, p.551) argue: "The primary task of ethical technology assessment [eTA] should be to identify potential ethical issues associated with a new technology." The next step is to employ measures that allow technologies that favour nature's ecological integrity to flourish. Palm and Hansson (2006, p.553) note: "Often, new technological products can be improved i.e., through the use of more recyclable materials and the introduction of efficient methods for implementing recycling." If proper recycling facilities, backed by policy, were abundantly available and sufficient, it is possible to view computers and other devices as environmentally neutral.

Research and development, under the eco-technological imperative, allow us to refocus how we make technologies that favour the environment's well-being and, in turn, we favour our well-being. This idea might seem far-fetched and overly ambitious. Yet, if it is promoted adequately, then a civilisation as ambitious as ours is must consider it to be 
a worthwhile and achievable goal. Feenberg (1999, p.69) argues: "A society that can destroy life on earth by the careless application of fluorocarbon deodorant sprays is indeed beyond the pale of any rational calculation of survival chances. History is over in principle in the sense that the old conflicts and ambitions must give way to a radically new type of human adventure, or else the species will surely die."

While Feenberg's former comment seems somewhat exaggerated, it nonetheless shows how the modern temper has not taken precautionary measures with technology even on the household scale. ${ }^{12}$ Feenberg shows that our environmental values are not well thought out by any means. It suggests that humankind's actions are not considerate of the well-being of the natural realm on which our survival ultimately depends. His latter contention suggests that humankind is in a position to come to grips with Jonas and Leopold, hence, the synthesised imperative. In the passage above, we can interpret 'ambitions' to include our technological undertakings. These need to be reoriented in a direction that is advantageous to environmental sustainability, which ultimately supports humankind. When environmental ethics and philosophy of technology come together, we can shed light on these dark matters.

\section{Technology and environmental policy}

Our discussion of research and development shows that if our technological activities regarded nature from the outset then we would not be caught up in an ecological crisis. The problem with policy is that it is rarely proactive. It is usually put in place after the damage is done. Policy, although a complexity itself, can help. We can categorise policies in the same way that we labelled technologies earlier. A policy can be good/bad or better/worse, depending on how it stands in relation to preserving the integrity, beauty, and stability of the biotic community with respects to technology. One of the main concerns is how to draft policies of this calibre. Luckily, there are models to follow.

For instance, in 2005, California passed the Electronic Waste Recycling Act, and retailers began collecting fees from consumers that would aid electronic recycling efforts. ${ }^{13}$ This policy had four key aspects: reducing hazardous materials used in electronics, facilitating electronic recycling, alleviating the cost of recycling electronics, and setting standards for the purchase environmentally friendly electronics. ${ }^{14}$ This policy, considering that it helps nature, is a good policy because it shows respect for nature's ecological integrity, similar to revealing technology. If technologies have environmental values embedded in them, then we can say that policies have these values embedded in them, too. Policies that foster care for nature reflect a higher level of concern than policies that permit industry to profit from exploiting nature. An absence of environmentally friendly policy indicates apathy toward nature. If the future of technology policy resembles that past, then the environment will still be in harm's way. Although, the public attitude is starting to take note of environmental concerns, policy ensures results.

We can conclude from Latour's (1992) work that simple technologies have moral principles embedded in them, which are governed by regulations. He highlights how the seatbelt is a technological device that implements the desires of the public (Latour, 1992). Through this device, regulations are set in place for Latour's (1992) well-being. These regulations dictate the right actions regarding his behaviour (Latour, 1992). In a similar fashion, California wants its citizens to be environmentally ethical when it comes 
to technology. By making regulations that dictate how outdated devices are to be disposed, California set standards that respect the integrity of nature. This is a good eco-technological policy.

Making environmentally friendly policy is a crucial step for alleviating some of technology's shortcomings. It requires careful thinking, but it is too important to discount. Jonas (1985, p.9) argues: "Public policy has never had to deal before with the issues of such inclusiveness and such lengths of anticipation. In fact, the changed nature of human action changes the very nature of politics." From this passage, we see that Jonas' call for a new type of ethics needs to be extended and reflected in policies regarding technology. Good technological policy will be helpful by taking the permanence of humankind and the environment as its goals. Since doing what is best for the environment is also what is best for humankind, good technology policy makes good sense.

\section{Concluding remarks}

When we examine the role that technology plays in environmental concerns, we can no longer look at it from the peripheral view. It must come to the forefront for us to address it sufficiently. We must look at philosophy of technology and environmental ethics in tandem. Although these disciplines are still relatively young, they cannot remain so distant. This type of synthesis is essential for dealing with these problems. What is more, those making decisions concerning technology and addressing the environmental impact assessment might want to consider the arguments put forth above because they call for similar requirements as the EIA. ${ }^{15}$ The not-so-subtle motif of this discussion is that what is good for the environment is good for humans when we question technology. This idea is why it is crucial for us to promote 'green technologies' in research, development, and policy. From the outset, this requires us to look at ourselves and keep a concern for nature firmly in view. After all, technology and environment do have one obvious common thread: us. The arguments presented here focused only on one possible approach to an environmental philosophy of technology or environmental ethics of technology, but more should come. If anything, this discussion shows how environmental ethics could benefit by an interdisciplinary approach. We can say that it is time for environmental ethics to extend into other related disciplines - or for other disciplines to extend into environmental ethics.

\section{Acknowledgements}

I would like to thank Nathan M. Bell, Jennifer Noonan, Carl B. Sachs, and an anonymous reader for their comments on an earlier draft of this paper.

\section{References}

California Integrated Waste Management Board (2009) available at $\mathrm{http}: / / w w w . c i w m b . c a . g o v / E l e c t r o n i c s / A c t 2003 /$ (accessed on 2 May).

Callicott, B.J. (1989) In Defense of the Land Ethic: Essays in Environmental Philosophy, SUNY Press, Albany, NY. 
Diamond, J. (2005) Collapse, Penguin Books, New York.

Environmental Protection Agency (2009a) available at ww.epa.gov/epawaste/conserve/materials/ecycling/faq.htm\#concern (accessed on 2 May).

Environmental Protection Agency (2009b) available at http://www.epa.gov/Region1/solidwaste/electronic/index.html (accessed on 2 May).

Feenberg, A. (1999) Questioning Technology, Routledge, New York.

Hargrove, E. (1992) 'Weak anthropocentric intrinsic value', in After Earth Day, University of North Texas Press, Denton, TX.

Heidegger, M. (1977, 1993) 'The question concerning technology', in Martin Heidegger: Basic Writings, David Farrell Krell, 2nd ed., HarperCollins Publishers, New York.

Jonas, H. (1985) The Imperative of Responsibility, University of Chicago Press, Chicago.

Latour, B. (1992) 'Where are the missing masses? The sociology of a few mundane artifacts', in Bijker, W.E. and Law, J. (Eds.): Shaping Technology/Building Society: Studies in Sociotechnical Change, MIT Press, Cambridge, MA.

Leopold, A. (1949, 1968) A Sand County Almanac, Oxford University Press, New York.

NEC Corporation of America (2009) available at

http://www.necam.com/press/read.cfm?Press_ID=6e201b56-3e09-4d7a-9d2e-111294a48b08 (accessed on 4 May).

Norton, B. (1984) 'Environmental ethics and weak anthropocentrism', Environmental Ethics, Winter, Vol. 6, pp.134-135.

Palm, E. and Hansson, S.O. (2006) 'The case for ethical technology assessment', Technological Forecasting and Social Change, Vol. 73.

\section{Notes}

1 Many disagree on the exact definition of weak anthropocentrism. For a better description, see Hargrove's (1992, pp.141-169). For another description, see Bryan Norton's (1984, pp.134-135). To better exhibit the ideas behind this concept, consider the following example. Efforts in city planning and sustainability are often weak anthropocentric. The environment and resources are maintained for human use now and for the future, yet, the environment benefits because of sustainability efforts. Since humans are the focus of sustainability, it is weak anthropocentric.

2 Ecological integrity, defined here in a limited and basic manner, holds that what is deemed 'natural' must be maintained now and into the future.

3 While Leopold's insights provide a conceptual principle, one must consider that if humankind fails to respect the limits of nature, societies will fail. For a detailed example, see Diamond's Collapse (2005, pp.79-119).

4 For a better description of ecocentrism, see Callicott, (1989, pp.3-4).

5 This form of weak anthropocentrism favours weak anthropocentrism as outlined by Hargrove (1992, pp.141-169).

6 Leopold's use of the term 'beauty' is problematic at this point because it is a question for aesthetics, and aesthetics questions are not a central concern in this paper.

7 At this point, we might want to consider that some technologies, such as automobiles, should be depended on less and replaced with systems of mass transit.

8 Environmental Protection Agency (2009b).

9 Environmental Protection Agency (2009a).

10 It is worth mentioning that technology could be 'environmentally neutral' if appropriate recycling centres and policies were in place to protect the environment.

11 NEC Corporation of America (2009). 
12 Even though we lack the ability to see long-term environmental consequences, researchers can at least be mindful of the environmental degradation and make significant attempts to prevent it. This approach may not optimally safeguard nature, but it is better than disregarding nature.

13 California Integrated Waste Management Board (2009).

14 Ibid. (accessed May 2, 2009).

15 For more information, available at http://www.iaia.org/modx/assets/files/Principles\%20of\%20IA_web.pdf. 